\title{
O TRABALHO DE TRADUÇÃO E O PROCESSO DE CONSTRUÇÃO CONCEITUAL: A DOBRA NA PERSPECTIVA DOS ESTUDOS INTERCULTURAIS EM EDUCAÇÃO
}

\begin{abstract}
Translation work and the conceptual construction process: the bend in the perspective of intercultural studies in education
\end{abstract}

Juliano Bona ${ }^{1}$

RESUMO: As dobras perturbam os espaços lisos e expressam modificações geográficas no meio observado. Existem diferentes tipos de dobras, as dobras sociais, filosóficas e culturais. Porém, pensar o conceito de dobra exige construção conceitual, trabalho de tradução, e posterior inteligibilidade. Desta forma, o objetivo geral desse artigo é, analisar a relação entre o conceito de dobra e suas implicações nos estudos interculturais em educação. Trata-se de um ensaio teórico. Iniciamos analisando as dobras no meio social, suas relações de intencionalidade e os mecanismos de subjetivação. Depois, no espaço filosófico, pensamos a dobra articulada ao plano de imanência e ao processo de construção conceitual. Em um terceiro momento, diante dos estudos interculturais em educação, as dobras representam as aproximações interculturais construídas no trabalho de tradução. Assim, o conceito de dobra exprimi, na dinâmica do pensamento, um sentido ético de criação conceitual, e edificação de afetos que possam ultrapassar a metáfora que a priori o sintetiza.

Palavras-chave: $O$ conceito de dobra. Estudos interculturais em educação. Tradução. Inteligibilidade.

ABSTRACT: Folds disturb smooth spaces and express geographical changes in the observed environment. There are different types of folds, social, philosophical and cultural folds. However, thinking about the concept of folding requires conceptual construction, translation work, and later intelligibility. Thus, the general objective of this article is to analyze the relationship between the concept of fold and its implications for intercultural studies in education. This is a theoretical essay. We begin by analyzing the folds in the social environment, their intentional relations and the mechanisms of subjectification. Then, in the philosophical space, we think of the fold linked to the plane of immanence and the process of conceptual construction. In a third moment, in the face of intercultural studies in education, the folds represent the intercultural approaches constructed in the

\footnotetext{
I Doutor em Educação pela Universidade do Vale do Itajaí - Univali (2020). Atua como professor de matemática na Rede Pública Municipal de Timbó/SC. Tem experiência no Ensino Superior nas seguintes áreas: Educação, Educação Matemática, Cálculo Diferencial e Integral, Geometria e Álgebra Linear. Desenvolve pesquisa na área da Educação, Educação Matemática, Processo de Internacionalização do Currículo (IoC), Estudos Interculturais, Intermatemática e Filosofia da Diferença. E-mail: bonajuliano@gmail.com.
} 
work of translation. Thus, the concept of bending expresses, in the dynamics of thought, an ethical sense of conceptual creation, and the building of affections that can overcome the metaphor that a priori synthesizes it.

Keywords: The concept of bending. Intercultural studies in education. Translation. Intelligibility.

\section{INTRODUÇÃO}

Quando pensamos nas palavras, conexão, intersecção e aproximação, nos remetemos à relação que existe entre diferentes espaços; se existe relação, intersecção, aproximação, pressupomos a diferença. Temos basicamente três tipos de imagens de pensamento que podem representar este movimento. Supomos que nossos espaços sejam círculos. Geometricamente, podemos ter a sobreposição de círculos (A): é quando um círculo está sobre o outro, neste caso a intersecção é o todo que representa um único espaço. Podemos ter círculos com uma pequena parte de sobreposição (B): assim, alguns elementos pertencem aos dois espaços ao mesmo tempo. E uma terceira situação: quando os círculos estão distantes (C) ou tangentes, onde não existe intersecção.

Imagem I: representação de espaços circulares no plano

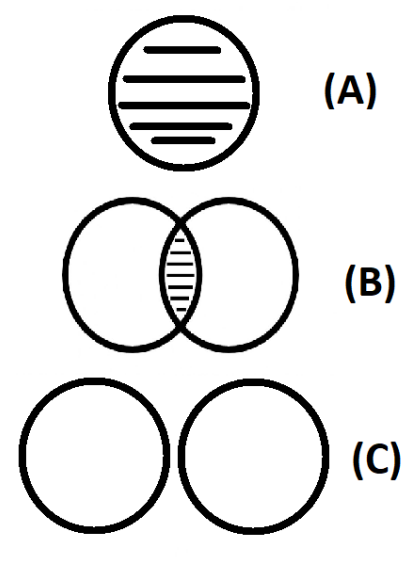

Fonte: o próprio autor

Podemos, diante destas imagens, pensar nas aproximações. $\mathrm{Na}$ situação (A), a aproximação, ou intersecção não faz sentido, pois os espaços já estão sobrepostos; a intersecção já atingiu seu maior formato. $\mathrm{Na}$ imagem (B), podemos pensar na intersecção, pois existe uma aproximação caracterizada por pontos que pertencem aos dois espaços. E no último caso $(\mathrm{C})$, não existem pontos de intersecção. Desta forma, nas três situações, estamos partindo de uma percepção de intersecção de espaços que existem a priori. Nesta análise dicotômica, ou se tem intersecção, em diferentes níveis, ou se tem a diferença, sem nenhum espaço de contato. Tudo está lá pronto; o que temos que fazer é diagnosticar as intersecções que já existem. 
Nesta esteira, estamos diante de uma contradição. Se partirmos de uma percepção a priori da existência de intersecções, o movimento de aproximação não faz sentido. Isso porque tudo que se conecta já está pronto. Se, por outro lado, pensarmos que as aproximações podem ser feitas a posteriori, diante de um movimento de construção das intersecções, podemos cair em um movimento que suspende os espaços a priori de intersecção em sentido vertical.

Precisamos construir as aproximações, mas sem tirar os pés do chão, sem sair do horizonte dos acontecimentos culturais e sociais. Pensemos a dobra. Acreditamos que ela seja uma possibilidade de pensarmos as aproximações, sem negarmos o processo de construção nem a geografia das intersecções existentes. Assim, o objetivo geral desse artigo é analisar a relação entre o conceito de dobra e suas implicações nos estudos interculturais em educação. Trata-se de um ensaio teórico, que articula as ideias dos seguintes autores: (BAUMAN, 2008, 2009), (CANDAU, 2002), (DELEUZE, 2002, 2005, 2010, 2017), (FOUCAULT, 2004), (FOUCAULT, 2013), (LEASK, 2015), (SANTOS, 2002). Partimos da hipótese de que se pensarmos a dobra como imagem do pensamento que expressa intersecção, aproximação e conexão entre diferentes saberes, temos a possibilidade de ampliar as discussões referentes aos diferentes saberes e culturas e seus pressupostos implícitos, no que se refere ao significado do movimento de aproximação por ele mesmo.

Este texto está dividido em três partes. Primeiramente, descrevemos o conceito de dobra em uma perspectiva social. Logo em seguida, deslocamos o conceito de dobra para um contexto filosófico, em um ambiente de construção conceitual. Em um terceiro momento, articulamos o conceito de dobra, situado no espaço filosófico, e os estudos interculturais em educação.

\section{As dobras no tecido social}

Quando estamos diante de uma superfície lisa, um pedaço de tecido ou de papel, a superfície de uma lâmina de água, ou diante de uma folha de uma árvore, a dobra, neste contexto, significa alguma perturbação, modificação. A dobra significa movimento de um tecido sobre a mesa, movimento do espaço de água, ou o choque de uma folha de árvore ao cair no chão. Superfícies sem dobras costumam ser estáticas, homogêneas; se existe movimento, ele acontece de forma constante e paralela, sem taxa de variação. Desta forma, as dobras indicam uma espécie de corte que se estende sobre as estruturas lisas.

Por um instante, pensemos nas diferenças entre o conceito de intersecção e dobra. As dobras modificam a geografia do espaço; um tecido liso pode se transformar em uma superfície cheia de dobras com a ação do vento que o empurra para o chão. A intersecção ou aproximação pressupõem a diferença. Ou seja, existem espaços diferentes que podem ser aproximados. Esta diferença carrega a priori as relações de poder que cada campo de saber possui em seu domínio histórico. Desta forma, as intersecções, antes de sua tessitura, carregam uma hierarquia na própria relação entre os diferentes saberes. Pensar em dobras é considerar que todos os saberes estão no mesmo plano. A diferença se expressa não por pertencer a espaços diferentes, como no conceito de intersecção, mas pelo local onde o ponto se encontra sobre um plano que expressa a multiplicidade na imanência. Não temos 
separação de campos de saber, mas, sim, uma geografia dos diferentes campos do saber. Uma geografia cheia de dobras, encontros e desencontros, todas pertencentes ao mesmo plano.

Se as dobras indicam modificação, podemos afirmar que existem diferentes dobras. Dobras na superfície, como no caso de uma montanha, dobras em uma folha de papel, que divide a área ao meio e aumenta o seu volume, ou a dobra na fita de Mobius, em que não existe a separação entre o lado de dentro e de fora em uma superfície de formato cilíndrico. Neste sentido, as dobras também objetivam a diferença por seus formatos e características. Podemos, também, pensar essa diferença por meio de sua causa, no estalar da causa. O que provoca uma dobra? Como surgem as dobras em uma superfície lisa? Para analisar estas respostas, parece prudente considerarmos o local e as características da superfície que estamos observando.

Nossa observação estende-se às relações interculturais, relações de poder, processos de subjetivação, transformações históricas e sociais. É sobre este plano que pensamos a dobra. Segundo Deleuze (2005), tudo no mundo existe dobrado. Sendo assim, estas múltiplas dobras do fora, produzem diferentes modos de expressão das subjetividades. As dobras, neste sentido, podem ser consideradas como pontos de inflexão onde se constitui certa relação consigo, os modos pelos quais se produz um dentro do fora. Desta forma, o conceito de dobra não é independente do campo social; a produção dos tipos de relação consigo e com o mundo é articulada por forças que circulam e constituem um determinado tecido social (DELEUZE, 2005).

Considerar as dobras em um campo social, pulverizado por diferentes culturas, é fazer, a princípio, um triplo movimento, quais sejam, movimento das dobras singulares produzidas pelas diferentes culturas; os deslocamentos históricos e as dobras produzidas de forma ampla; e os processos de subjetivação. Estas três camadas formam o que poderíamos denominar de arqueologia das dobras sociais. Assim, os movimentos de transformação social, dirigidos de forma singular em nível cultural, se projetam nos mais diferentes mecanismos de subjetivação. As dobras, nesse sentido, produzem movimentos de descontinuidade que se dobram sobre os processos de subjetivação.

Nesta esteira, as dobras no tecido social ganham um dimensão infinitesimal na análise dos mecanismos de subjetivação. Temos uma aproximação entre os movimentos sociais e culturais com os sujeitos que a compõem. Deleuze (2005) menciona que as relações de poder, típicas das sociedades disciplinares e de controle, envergam o lado de fora (poder) para uma constituição de "uma relação da força consigo, um poder de se afetar a si mesmo, um afeto de si por si” (DELEUZE 2005, p.108). Há, nesse sentido, uma tecnologia de poder que organiza as dobras pertencentes ao tecido social onde os sujeitos estão mergulhados. As tecnologias de si derivam desse processo onde a relação sujeito sociedade é literalmente dobrada.

As tecnologias de si variam culturalmente e desenvolvem uma relação de dependência com os outros sujeitos que as constituem. Estas tecnologias de si permitem aos indivíduos efetuar, com seus próprios meios ou com a ajuda dos outros, "um certo número de operações em seus próprio corpo, almas, pensamentos, conduta e modo de ser, de modo a transformá-los com o objetivo de alcançar um certo estado de felicidade, pureza, sabedoria, perfeição ou imortalidade" (FOUCAULT 2004, p.324). É neste ponto que o conceito de dobra em uma perspectiva social se objetiva. "O lado de fora não é um limite fixo, mas uma 
matéria móvel, animada de movimentos peristálticos, de pregas e dobras que constituem um lado de dentro: nada além do lado de fora, mas exatamente o lado de dentro do lado de fora" (DELEUZE 2005, p. 104).

Vale destacar que estamos diante de uma análise topológica dos modos de subjetivação. O conceito de dobra sintetiza esta abordagem e rompe com a dicotomia dentro - fora, no que se refere à relação sujeito - sociedade. As relações de força que circulam no meio social, por conseguinte, devem vergar e dobrar, para, com isso, desenvolver uma nova forma de se relacionar consigo, que não seja apenas de constrangimento e domínio dos códigos, mas também de capacitação e domínio da ética. Que seja, desta forma, "uma relação de força consigo, um poder de se afetar a si mesmo, um afeto de si por si" (DELEUZE 2005, p.ro8). As forças que agem no meio social continuam sendo as relações de saber poder, porém, foram dobradas, sem deixarem de ser forças.

As dobras do lado de fora que se constituem do lado de dentro dependem dos parâmetros institucionais inseridos na proximidade do sujeito. Foucault (2004) insiste que a relação de afeto de si por si é uma derivada, uma dobra, uma curvatura da superfície do fora. Deste modo, o dentro é um espaço onde as agitações do fora se cristalizam, perdendo a densidade e a agitação. $O$ fora se realiza no sujeito e se projeta em seu corpo, em um movimento contínuo de substituição do dentro e atualização de um outro que se perfila a cada mudança de rota. Estamos diante de um processo que cria uma estética da existência por meio de dobras, uma espécie de topologia da existência onde sujeito e sociedade formam uma única trama no tecido social.

Como consequência imediata, podemos, diante desse ponto de vista, afirmar que as dobras situadas no contexto social implicam uma não separação entre sujeitos e sociedades. As culturas e os mecanismos de subjetivação são considerados como um único tecido que se modifica, que se torce, que se dobra. Porém, muitas observações podem ser feitas. Podemos pesar em dobras tensionais, fraturas que aparecem ao longo da história, como a passagem do empirismo ao racionalismo, ou a decadência dos discursos universalizantes na pósmodernidade, dobras que surgem no fractal dos acontecimentos sociais dispersos, desprovidos de um autor que o acompanhe. Por outro lado, e não descolado das dobras tensionais, podemos pensar na arquitetura das dobras intencionais. Estas se articulam à intenção de se construir dobras, ao movimento de se construírem conceitos, ao processo de tradução, e à construção de inteligibilidades.

Estes processos podem ser pensados em diferentes territórios, como os territórios conceituais, filosóficos, epistemológicos, sociológicos, e culturais, todos com suas particularidades e implicações. Em nível cultural, como veremos adiante, as dobras se expressam nas relações interculturais de forma intencional. Porém, antes de analisarmos estas relações que se efetivam em nível cultural, precisamos especificar as ferramentas que nos permitem observar e construir conceitos.

\section{A dobra e suas implicações filosóficas}

Depois de analisarmos as dobras em um contexto social, pensemos a dobra como um ato intencional. Deste modo, estamos diante de uma arquitetura das dobras, um processo de construção de dobras. E é neste ponto que situamos o conceito de dobra no campo da 
filosofia. Segundo Deleuze (2010), a filosofia é a arte de formar e construir conceitos. Deste ponto de vista, a filosofia é o campo onde se situa as ferramentas que possibilitam a construção de conceitos. Porém, estamos diante da construção de um conceito específico, com suas particularidades, cifra, e velocidade de locomoção. Além disso, o conceito de dobra carrega em sua estrutura uma blindagem que permite suspender outros conceitos, em um ralação de intenção analítica.

Nesse sentido, o conceito de dobra está situado na filosofia, não no que se refere à construção conceitual, mas sim àquilo que o sustenta, ou seja, o plano de imanência. Deleuze (2oro, p.52) afirma "que os conceitos são acontecimentos, mas o plano é o horizonte dos acontecimentos, o reservatório ou a reserva de acontecimentos puramente conceituais". É sobre o plano de imanência que os conceitos circulam, se encaixam, como um conjunto de ladrilhos que preenchem a superfície de uma parede. "É por isso que há sempre muitos movimentos infinitos presos uns aos outros, dobrados uns nos outros, (...), de tal maneira que o plano de imanência não para de se tecer, gigantesco tear" (DELEUZE 2010, p.54).

É sobre a ideia de plano de imanência que podemos fazer a primeira aproximação sobre o conceito de dobra. Se a filosofia é a arte de construir conceitos e o conceito está sobre um determinado plano de imanência, a dobra neste contexto representa a junção de um conjunto de conceitos que se atualizam a cada novo atrito. A dobra representa o ato de se construírem conceitos em uma topologia de acontecimento específico. Como exemplo, tomemos como referência o plano de imanência cartesiano. Deleuze (2010) sinaliza que o cartesianismo não expressa apenas um movimento que tem como devir a luz da racionalidade; além disso, e também, objetiva a arquitetura de um plano de imanência que legisla o que pode ou não ser pensado. Desta forma, o conceito de sujeito cartesiano, que pode ser confundido como característica inata de qualquer ser humano, ganha uma roupagem metafísica de busca pela verdade, diante de uma metodologia que subtrai o sujeito criador. Por outro lado, segundo Bauman (2009), vivemos em uma sociedade pós-moderna que se caracteriza por sua liquidez, onde os acontecimentos e relações intersubjetivas se movem de forma fluida, sem engates, sem rigidez. Neste plano de imanência, o conceito de sujeito se aplica a um ambiente fluido, onde o sujeito é o representante desta dinâmica, que se escoa em direção a um consumismo deliberado. Diante destes dois planos, o conceito de sujeito racional e liquido pode ser dobrado em um movimento que constrói convergências e divergências. É a dobra, ou melhor, a arquitetura intencional de se construírem dobras conceituais que caracteriza o campo da filosofia.

Podemos afirmar que os conceitos e suas relações expressam dobras. Porém, existe outra maneira de se pensar a dobra em nível de suporte, levando em consideração os espaços de possibilidade, os agenciamentos conceituais, ou seja, o plano de imanência. Plano geométrico, plano abstrato, plano de pensamento, todos caracterizam um conjunto de partes menores posicionados lado a lado. Esta característica não nega a existência de um conjunto de planos, de uma rede de planos, de uma sobreposição de planos folhados. Deleuze (2010, p.68) afirma que "deve-se então supor uma multiplicidade de planos, já que nenhum abraçaria todo o caos sem nele recair, e que todos retêm apenas movimentos que se deixam dobrar juntos”. Desta forma, os planos de imanência não são definidos apenas como um conjunto de pontos posicionados lado a lado como quer a geometria euclidiana. O plano de 
imanência ganha profundidade que risca a próxima dimensão, é composto por um conjunto de folhas, camadas que se atualizam a cada acontecimento histórico.

Neste contexto, estamos em outro nível da dobra. São os diferentes planos de imanência que se dobram em uma espécie de expansão de dobras que ultrapassam a miniatura dos conceitos. Não se trata de dobrar uma totalidade que contempla um conjunto de conceitos que a pertence, nem de dobrar espaços separados com limites de território bem marcados, mas, sim, em dobrar o horizonte de acontecimentos, os caminhos que o conceito percorre para mostrar suas linhas de contorno. Neste ponto, caímos novamente sobre a relação entre o múltiplo e o uno. Ou seja, como delimitar um plano de imanência? Deleuze (2010) indica que os grandes filósofos construíram grande plano de imanência: Descartes, Platão, Heráclito e Parmênides. Nesta vertente, a identificação está articulada ao pensamento do filósofo, e é neste espaço que o plano se estrutura. Porém, o plano não está flutuando, isolado da história; ele se atualiza a cada novo discurso, a cada nova justificativa de ação. "E se não pode se escapar a isso, é porque cada plano de imanência, ao que parece, não pode pretender ser único, ser $\mathrm{O}$ plano, senão reconstituindo o caos que deveria conjurar: você tem a escolha entre a transcendência e o caos..." (DELEUZE 2010, p.70).

Em uma perspectiva filosófica a aproximação do conceito de dobra se apresenta como uma geografia. Uma geografia do pensamento que permite a criação conceitual e que estende a possibilidade de pensar a diferença na imanência. $O$ conceito de dobra expressa essa pretensão de pensar geograficamente as aproximações em diferentes áreas do conhecimento. Conhecimentos que circulam na terra, agenciados por uma rede de discurso que celebra uma segunda intenção. Pensar o conhecimento nesta perspectiva é considerar as diferentes culturas, as relações de poder e os mecanismos que institucionalizam estes saberes nos currículos e nas universidades. Doravante, cabe a nós pensarmos em dobras, nas dobras dos conhecimentos, não apenas como funcionários do conhecimento hegemônico, mas como construtores que caminham nas periferias, nos lixões epistemológicos onde os intelectuais legisladores não ousariam sujar seus pés.

Falta-nos frisar um último ponto. Pensamos nos conceitos, nos planos que atravessam e filtram nosso olhar por meio de dobras. Deste ponto de vista, corremos o risco de cairmos em uma análise pautada em um relativismo absoluto, que considera as dobras apenas como um processo de abstração. Se temos a pretensão de construir dobras conceituais que pertencem a diferentes planos de imanência, precisamos considerar a caminhada do observador e as forças que nos atingem social e culturalmente. Precisamos analisar dobras perceptíveis, dobras que arrastam o olhar para um único ponto. São máquinas de dobras, ou seja, a grande máquina do capitalismo contemporâneo.

Vivemos em uma sociedade capitalista pautada no consumismo. Segundo Bauman (2008, p.7I), vivemos em uma sociedade de consumidores, "em outras palavras, representa o tipo de sociedade que promove, encoraja ou reforça a escolha de um estilo de vida e uma estratégia existencial consumistas, e rejeita todas as opções culturais alternativas”. Deste modo, não se definem apenas as características sociais e sua dinâmica de organização consumista; o que se tem é a condição de afiliação que nos transforma em consumidores. Estamos diante de um exemplo de dobra, uma dobra específica, que transforma a estética social de consumo em um conjunto de afetos que nos empurram silenciosamente para uma lógica de devir consumidores - consumo logo existo. 
Se é esta lógica do consumismo que nos interpela, se é sobre este plano de imanência que circulamos, as dobras que construímos, as aproximações que fazemos, nos mais diferentes campos conceituais, são influenciadas por esta dinâmica. Ter consciência de não estar no vazio, no momento de traduzir diferentes conceitos, diferentes espaços epistemológicos, nos permite não apenas combater as hegemonias que são perpetuadas na grande maioria dos espaços universitários, mas sim, e principalmente, instalar uma vigilância que questiona os motivos de se construírem dobras entre as diferentes áreas do conhecimento. Se estamos construindo aproximações, ou dobras em um contexto filosófico, que estas expressem a vontade de construir novos espaços, e não de atender uma demanda de afiliação social que transforma tudo em produto, tudo em objeto, tudo em consumo. Nesta perspectiva, e com o objetivo de retomar a gênese do conhecimento humano, temos a ossibilidade de construir dobras entre as diferentes culturas. Culturas em um sentidoeográfico e de soterramento, consequência imediata de uma sociedade que nos define como consumidores.

\section{A dobra e os estudos interculturais em educação}

Primeiramente, analisamos o conceito de dobra e suas consequências no contexto social. Neste espaço, o conceito de dobra ultrapassa a percepção das modificações sociais distantes dos mecanismos de subjetivação. As dobras, nesse sentido, expressam as modificações que ocorrem no tecido social e sua relação com os processos de subjetivação, ou seja, dobra-sujeito-sociedade. Em um contexto filosófico, observamos a intencionalidade de se construírem dobras, no construto conceitual e no plano de imanência. Logo em seguida, exemplificamos este ponto de vista por meio de dobras que pertencem ao nosso momento histórico, a dobra sociedade de consumo e sujeito consumidor.

Se partirmos do pressuposto que a diferença entre os povos se atualiza por meio das diferentes culturas, o conceito de dobra também segue esta transformação e parte de outros pontos. Seu princípio continuam sendo sociais, filosófico, articulado a intencionalidade do construtor, porém, o substrato que o alimenta é outro. A matéria prima que sustenta as dobras são as diferentes culturas e suas relações. Contudo, estas dobras podem ser pensadas como uma sobreposição espontânea entre as mais variadas culturas ou como um trabalho que exige tradução. Acreditamos que os dois caminhos se complementam, mas é na intencionalidade da tradução e no ato de se construir conceitos sobre o plano de imanência, que as dobras ganham um sentido filosófico.

Desta forma, as dobras interculturais são construídas por um tradutor. Neste sentido, estamos diante de três aspectos: a matéria que constitui o espaço, as dobras, e o tradutor. No que se refere à matéria que constitui os espaços, estamos diante de uma percepção da diferença que se objetiva por meio das múltiplas culturas. Ou seja, partimos do pressuposto de que existem diferentes culturas, e que as mesmas podem ser localizadas formalmente, através dos hábitos, material simbólico que constitui a identidade visível, sua ciência e religião. Culturas que se caracterizam por grandes e pequenos discursos, todas identificáveis com limite próprio. Esta percepção da diferença no material que constitui o fazer humano, Candau (2002) chama de multiculturalismo, que "possui simultaneamente um sentido descritivo e um normativo, ou prescritivo" (p.42). Descritivo, no sentido de afirmar que a 
realidade é multicultural, e prescritivo, por situar a definição de uma corrente que expressa a diversidade em grupos que já são diversos e multiculturais. A diversidade, desta forma, parece ser alérgica aos limites semânticos que uma temática exige para se caracterizar como tal, assim, a definição de multiculturalismo normatiza a diversidade cultural em seu formato mais refinado.

A perspectiva intercultural se depara com o mesmo limite, qual seja, diante da diversidade cultural, construir um conjunto de conceito que permita observar as diferenças sem diminuir sua velocidade. E é neste ponto que situamos o conceito de dobra. Segundo Candau (2002, p.44), a perspectiva intercultural "não concebe as culturas como estados, como entidades independentes e homogêneas, mas a partir de processos, de interações, de acordo com uma lógica da complexidade". Deste modo, não negamos que a realidade é multicultural, porém, destacamos que é nas relações interculturais que situamos as dobras. É no conflito, no cruzamento entre os diferentes discursos interculturais que a lógica da complexidade se efetiva.

Podemos afirmar, nesse sentido, que em nível cultural, as relações interculturais formam uma espécie de topologia das dobras. As dobras formam um sistema de referência geográfico que nos prendem na imanência e expressam a lógica da complexidade. Analisar a complexidade das relações interculturais é negar sua complexidade. Por outro lado, negar as interações sociais complexas é arquitetar um espaço de observação externo, ou seja, a criação de um espaço transcendente. Trata-se de uma escolha, como afirma Deleuze (2010), entre a complexidade e a transcendência. Se estamos no espaço intercultural, geográfico, imanente ao fazer humano, estamos na trilha da complexidade.

Contudo, corremos alguns riscos. Considerar a complexidade como mecanismo que justifica as interações interculturais pode levar-nos à produção de ausências e inibir as aproximações e a construção de inteligibilidade. Além disso, considerar a complexidade como parâmetro de interação pode fazer com que nosso olhar caia em um relativismo absoluto, sem direção, sem detalhamento, e principalmente, sem pontos de interação entre as diferentes culturas. Diante disso, assumir que as interações interculturais se efetivam por meio de uma lógica da complexidade e que, ao mesmo tempo, permita frear a complexidade em uma espécie de espaço composto por aberturas intencionais de contato com as complexidades. O plano de imanência, o processo de construção conceitual, sugerida por Deleuze (2010), e o conceito de dobra, nos ajudam a construir este espaço sem desconsiderar o complexo.

Depois de analisarmos a matéria que constitui o espaço e as dobras, ou seja, a matéria multicultural e as relações interculturais, podemos pensar na intencionalidade de construir dobras, no trabalho de tradução e no sujeito tradutor. Santos (200o) afirma que o trabalho de tradução pressupõe a criação de consensos transculturais. É uma teoria que afirma a impossibilidade de se construir uma teoria geral. Sem este pressuposto, o trabalho de tradução é apenas mais uma ferramenta de colonização epistemológica. Desta forma, o trabalho de tradução permite construir inteligibilidade entre diferentes discursos culturalmente estabelecidos. As fatias desses discursos vão depender da aproximação e do local de escolha. Podemos pensar na tradução intercultural das diferentes matemáticas, religiões, ou tomar como referência os parâmetros discursivos que pertencem aos diferentes Estados, ou até mesmo um conceito específico, como a ideia de natureza, construída pelos 
povos indígenas, americanos. A tradução pode tocar em um discurso amplo que atravessa grande parte do território cultural, ou reduzir a análise a um conceito teórico específico, pertencente a uma vertente já tematizada culturalmente. Largo ou estreito, o trabalho de tradução se caracteriza por este processo de tornar as diferenças em diferenças comuns.

Entretanto, o tradutor não está sozinho. O tradutor não é neutro nesse processo. Os mecanismos de subjetivação, as dobras estabelecidas na relação sujeito e sociedade, a resultante desse processo criam um sistema de referências, que, em última análise, espia sobre os ombros do tradutor. Deste ponto de vista, podemos nos perguntar: no trabalho de tradução, quem é a terceira pessoa que espia sobre nossos ombros? Não importa a origem do tradutor, português, brasileiro, holandês ou africano, as dobras que constituem o tradutor se caracterizam como uma variável importante, que muitas vezes se impõem sobre o material traduzido. Isto não significa a negação dessa variável, ou o encolhimento da subjetividade no trabalho de tradução; o que se tem é apenas um movimento de inserção do tempo, da história e das culturas, por meio de um terceiro que nos observa sobre os ombros no trabalho de tradução.

Existe um último ponto a ser analisado. Vimos que o conceito de dobra em uma perspectiva intercultural inclui sua matéria, quais sejam, a dobra e o trabalho de tradução. Porém, a retomada de aspectos sociais, subjetivos e filosóficos possibilita a construção de espaços dobrados onde o trabalho de tradução se encadeia em duas vias. Duas vias interligadas, juntas, unidas na tradução. A primeira se caracteriza pela tradução do próprio tradutor; estamos diante de um movimento de tomada de consciência sobre o que nos constitui e a maneira com que estas forças se projetam na realidade observada. "Estamos certos de que o encadeamento das ideias reproduz a realidade como tal" (DELEUZE 2017, p.I5I). Observar a si mesmo no trabalho de tradução é colocar o sujeito como expressão de correntes discursivas que o atravessa e o constitui. A segunda se refere aos discursos materializados e situados culturalmente e à intencionalidade de se construírem aproximações. Desta forma, e desse ponto de vista, o trabalho de tradução permite construir subjetividades e aproximar conceitos multiculturais, ou seja, estamos diante de uma perspectiva que se projeta no olho do sujeito intercultural.

Diante desse contexto, pensar as dobras interculturais na educação, com o objetivo de promover um movimento de construção de inteligibilidade intercultural, exige um alinhamento metodológico que se adapte inicialmente à estética organizacional, institucional e discursiva que pertencem ao espaço educacional. Segundo Foucault (2013, p.I43), desde o século XVIII as escolas, os hospitais e os manicômios se transformaram em mecanismos de disciplinamento que se constituíram como "quadros vivos" que transformam as multidões confusas em multiplicidades organizadas. Estética que transforma o espaço em quadros e que impede a acomodação imediata do diferente. Neste sentido, Leask (2015) formula um processo que permite vincular sistematicamente os estudos interculturais à educação por meio do currículo. O processo de internacionalização do currículo - IoC permite, por meio de estágios, imprimir uma perspectiva intercultural no campo da educação. A IoC, desta forma, nos permite pensar na adaptação da diferença bem como no processo de construção de dobras, posterior ao alinhamento estético educacional e metodológico. São a metodologia e a sistematização modeladas pela IoC que nos permitem instalar a construção de dobras no espaço educacional. 
Partirmos do pressuposto de que podemos construir dobras interculturais e que este processo implica transformações discursivas e subjetivas. Neste sentido, o plano de imanência não servirá apenas como metáfora das dobras em um ambiente geográfico dobras culturais, dobras das diferentes matemáticas, dobras conceituais situadas culturalmente, dobras ideológicas, dobras epistemológicas. Analisar o conceito de dobra e sua relação com os processos de subjetivação nos coloca diante de uma concepção de imanência que ultrapassa a dinâmica dos mecanismos de sujeição social. Construir dobras significa pensar na imanência, onde o espaço não subtrai o sujeito nem seu poder de criar conceitos. Deleuze (2002) menciona que é na imanência que as possibilidades de interação se efetivam e a diferença se atualiza. Ou, dito de outra forma, é no espaço da ética dos encontros interculturais que as dobras podem ser construídas. Talvez, e pensando em um espaço de possibilidades, o ponto inicial para se discutir as perspectivas interculturais em educação seja o resgate do construtor que vive em nós, do autor da diferença. Na matemática, na história, ou na geografia, não importa a temática, as aproximações e as intersecções serão feitas por sujeitos, os sujeitos cartesianos, sujeitos capitalistas, sujeitos consumistas, sujeitos andantes, sujeitos que se constituem nos dobrados.

\section{Considerações}

Nosso objetivo foi analisar a relação entre o conceito de dobra e suas implicações nos estudos interculturais em educação. Para isso, pensamos no conceito de dobra em uma perspectiva social, filosófica, e educacional. Social, na relação sujeito - sociedade, filosófica - na imanência e na construção conceitual, e no contexto dos estudos interculturais em educação. O conceito de dobra exprime uma perspectiva que não nega as interações sociais de modificação, e também não exclui as marcas desse movimento, nem os mecanismos de subjetivação.

Pensar em dobras é observar aquilo que nos atinge como um campo de forças feito por movimentos de ruptura, descontinuidades, relações de saber poder. É criticar os pressupostos de retirada transcendental, ou a hipótese de um sujeito transcendental que tudo observa, e que tem acesso a uma verdade reluzente e verdadeira. As dobras nos colocam no chão, nos espaços de interação social, cultural, no círculo dos discursos nômades.

Deste modo, aproximações podem ser feitas entre os diferentes conhecimentos, saberes que circulam nas universidades e nas escolas. Pacotes semânticos fechados, camuflados por universalidades que se projetam nas linguagens científicas, como na matemática e na química. Nesta esteira, nos deparamos com um último ponto. Quando não compreendemos uma regra de três, nós a aplicamos, nós a consideramos como um dever. Relações matemáticas consideradas universais, como a relação de proporcionalidade que envolve a regra de três passam a atuar no campo social, formando listas de prescrição que atuam de forma moral, transcendente, excludente. A moral e as relações científicas universais passam a formar um único discurso que prescreve tudo que se aproxima, tudo que não se iguala.

Se pretendemos promover aproximações entre diferentes saberes, que este não seja para criar uma moral das aproximações, ou uma lista de como se deve promover a construção de estudos interculturais em educação. Ao contrário, nossa pretensão deve ser a de, a partir 
da imanência, pensarmos em dobras, em espaços geográficos culturalmente estabelecidos. Se o conceito de dobra for apenas mais uma imagem no pensamento que força a ciência a se diluir na sociedade na forma de discurso morais prescritivos, estamos diante de apenas mais uma imagem que se presta flutuante. De outro modo, se o conceito de dobra exprimir, na dinâmica de pensamento, um sentido ético de criação conceitual, os afetos provocados por este conceito podem ultrapassar a metáfora que a priori o sintetiza. Que a universidade possa ser um espaço de dobras em que a ética dos encontros se sobreponha ao das prescrições.

\section{Referências}

BAUMAN, Z. Modernidade líquida. Rio de Janeiro: Jorge Zahar, 2009.

BAUMAN, Zygmunt. Vida para consumo: a transformação das pessoas em mercadoria. Rio de Janeiro: Jorge Zahar Editora, 2008.

CANDAU, V. M. Sociedade, Educação e Culturas(s). Rio de Janeiro: Vozes, 2002.

DELEUZE, Gilles. Foucault. São Paulo: Brasiliense, 2005.

DELEUZE, G. e GUATTARI, F. O que é a filosofia? São Paula. Editora 34. 2010.

DELEUZE, G. Espinosa: filosofia prática. São Paulo. Editora: escuta. 2002.

DELEUZE, Gilles. Espinosa e o problema de expressão. São Paulo: Editora 34. 2017.

FOUCAULT, Michel. Tecnologias de si. Verve, PUC, São Paulo, n. 6, p. 321-36o, out. 2004 .

FOUCAULT, M. Vigiar e Punir. Editora Vozes, São Paulo, 2013.

LEASK, B. Internationalizing the curriculum. Abingdon: Routledge, 2015.

SANTOS, B. S. Para uma sociedade da ausência e uma sociedade das emergências. Revista crítica das ciências sociais, 2002. p. 237-280. 